\title{
Çocuklardaki osteopenik hastalıklarda medikal tedavi
}

\author{
Medical treatment of osteopenic diseases in children
}

\author{
Yaşar Şen \\ Selçuk Üniversitesi Tıp Fakültesi, Çocuk Sağlığı ve Hastalıkları Anabilim Dalı, Çocuk Endokrinoloji Bilim Dalı, Konya
}

Osteoporoz, çocukluk çağının nadir bir hastalığıdır. Primer veya sekonder nedenlerle meydana gelmektedir. Günümüzde çocuk ve adolesan osteopenisi için herkes tarafından kabul görmüş bir medikal tedavi protokolü bulunmamaktadır. Bu nedenle, hekimlerin tecrübesi ve bireysel tedavi yaklaşımları önem arz etmektedir. Asıl yapılması gereken şey, riskli bireyleri tespit etmek ve osteopeni gelişimine engel olmaktır.

Anahtar sözcükler: osteopeni; çocuk; medikal tedavi
Osteoporosis is a rare disorder of childhood. It occurs due to primary or secondary causes. There is not a generally accepted medical treatment protocol for osteopenia of children and adolescents in our day. Therefore, physicians' experience and individual treatment approaches gain importance. What can be done basically is to identify individuals with risk, and prevent the development of osteopenia.

Key words: osteopenia; child; medical treatment

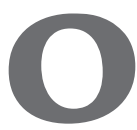

steoporoz, kemiğin mikro-mimarisinde bozulma sonucu kemik kütlesinde azalma, buna bağlı olarak kırılganlığında ve kırık riskinde artma ile karakterize, ilerleyici bir iskelet sistemi hastalığıdır. ${ }^{[1]}$ Albright ve Reifenstein tarafından 1948 yılında tanımlanmasına rağmen, hep erişkin hastalığı olarak kabul edildiğinden, yakın zamana kadar çocukluk çağına ait ayrıntılı değerlendirmeler yapılmamıştır. ${ }^{[2]}$

Çocuklarda kronik hastalıkların tedavisinde modern yöntemlerin devreye girmesi ve eskiden kısa olan yaşam sürelerinin bu hastalarda uzaması, organ nakillerinin sık yapılıyor olması, kemik üzerine olumsuz etkileri bulunan birçok yeni ilacın farklı hastalıklarda zorunlu olarak kullanılması ve tanısal metodlarının ülke genelinde yaygınlaşmasıyla, çocuklardaki osteoporozun önemi yeni anlaşılmaya başlamıştır. ${ }^{[3]}$

Çocukluk çağı osteopenik olgular genellikle gözden kaçmaktadır. Hastaların birçoğuna tanı, başka nedenlerle istenilen tetkiklerin değerlendirilmesi sırasında konulmaktadır. Tanı gecikmesine bağlı morbiditelerin önüne geçilebilmesi için, klinisyenlerin osteopeniyle ilişkili riskli durumları ve tanıyı akılda tutmaları, her türlü kronik hastalıkta mutlaka multidisipliner yaklaşım yapmaları gerekmektedir.

Çocukluk çağında kemik boyutları, mineral ve kollajen yapısı ve kemik yoğunluğu üzerine pek çok faktörün etkisi bulunmaktadır. Bunların yaklaşık \%80'ini genetik, geri kalanını ise çevresel faktörler (beslenme, egzersiz, hormonlar) oluşturur. ${ }^{[4,5]} \mathrm{Bu}$ faktörlerin bir kısmı kemik yapımı, diğer bir kısmı ise kemik yıkımı üzerine etki gösterir. Eğer olumsuz etkilenme fazla ise osteoporoz ve buna bağlı olarak basit bir travmayla, kırıklar, iskelet ağrıları, kemik deformiteleri ve hareket kabiliyetinde azalma meydana gelir.

\section{OSTEOPOROZ SIKLIĞI VE NEDENLERI}

Osteoporoz çocukluk çağında nadir görülür. Dünya çapında sıklığı ile ilgili yeterli veri bulunmamaktadır. Ülkemizde yapılan bir çalışmada görülme oranı \%1,1 tespit edilmiştir. ${ }^{[6]}$ Nedenler göz önüne alındığında, osteoporoz primer ve sekonder diye ikiye ayrilmaktadır. Tüm osteoporozluların yaklaşık \%20'sini primer (kemik matriks defektleri), \%80'ini ise sekonder osteoporoz (kronik hastalıklar, nöromusküler hastalıklar,

- İletişim adresi: Prof. Dr. Yaşar Şen, Selçuk Üniversitesi Tıp Fakültesi, Çocuk Sağlığı ve Hastalıkları Anabilim Dalı, Alaeddin Keykubat Yerleşkesi, Selçuklu, Konya Tel: 0332 - 2412181 e-posta: yasarsen1@yahoo.com

- Geliş tarihi: 8 Ağustos 2016 Kabul tarihi: 8 Ağustos 2016 
endokrin hastalıklar, doğumsal metabolik hastalıklar, ilaçlar, radyoterapi) olguları oluşturmaktadır. ${ }^{[6]}$

Primer osteoporoz grubunda, idiyopatik juvenil osteoporoz ve herediter kemik matriks defektleri (osteokondrodisplaziler $=$ dismorfik kemik hastalıkları) yer alır. ${ }^{[4,7]}$ Kas iskelet sisteminin dismorfik hastalıkları, fetal hayattan itibaren yaşamın herhangi bir döneminde belirti verebilen, tutulum yerleri, klinik özellikleri, laboratuvar bulguları, komplikasyonları ve prognozları birbirinden farklı, genetik kökenli, nadir görülen, çok çeşitli tipleri olan bir grubu kapsar. ${ }^{[8]}$ Dismorfik hastaların osteoporozunda sadece primer kemik rahatsızlığı rol oynamamakta, ilaveten hareket kısıtlılıkları, deformiteler, beslenme bozuklukları, vitamin ve mineral eksiklikleri, hormonal bozukluklar, kullanılan ilaçlar gibi birçok faktörün de katkısı bulunur.

\section{OSTEOPOROZ TANISI}

Osteoporoz tanısı, öykü, fizik muayene ve laboratuvar bulguları göz önüne alınarak konulmalıdır. Öyküde; akrabalık, beslenme, hastanın vitamin $D$ ve kalsiyum desteği alıp almadığı, büyüme ve gelişmesi, geçirdiği hastalıklar ve operasyonlar, fiziksel aktivitesi, atravmatik kırık, bel, sırt ve ekstremite ağrıları, kullandığı ilaçlar, radyo-kemoterapiler sorgulanmalıdır. Muayene sistemik olarak yapılmalı, dismorfik hastalıkları destekleyen tipik bulguları, puberte evresini, antropometrik ve vital ölçümleri içermelidir. İ̧̧itme kaybı, mavi sklera, diş bozuklukları, vücut oranlarında orantısızlık, boy kısalığı ve büyüme hızında yavaşlama gibi osteoporozun zemininde yatan hastalığın işaretleri gözden kaçırılmamalıdır.

Laboratuvar incelemeleri, düşünülen nedene göre planlanmalıdır. Başlangıçta basit tetkikler, gerekli ise daha ayrıntılı incelemeler yapılmalıdır. Özellikle hemogram, elektrolitler, böbrek ve karaciğer fonksiyonları, kalsiyum, fosfor, alkalen fosfataz, idrar kalsiyum ve kreatin düzeyleri, $25-\mathrm{OH}$ vitamin $\mathrm{D}$, tiorid, paratiroid ve kalsitonin hormonları, ekstremite ve vertebra grafileri, Dual Energy X-ray Absorptiometry (DEXA) ile ölçülen kemik mineral dansitesi (KMD) incelemelerde yer almalıdır. ${ }^{[9,10]}$ Risk taşımayan ya da hastalık belirtisi olmayan çocuklarda, gelişigüzel ve rutin DEXA tetkiki istenilmemelidir.

Osteoporoz tanısında kullanılan kemik mineral ölçüm yöntemlerinin hemen hepsi erişkinlere göre düzenlenmiştir. Erişkinlerde kullanılan metodların birçoğu maalesef çocukluk çağı pratik yaklaşımında yer bulamamaktadır. Doğru bir değerlendirme için; kemik mineral içeriğini (gram), kemik alanını $\left(\mathrm{cm}^{2}\right)$ ve kemik volümünü $\left(\mathrm{cm}^{3}\right)$ elde etmek gerekir. Bu veriler mutlaka ırk, yaş ve cinsiyete göre sağlıklı gruplardan elde edilen normal değerler ile, yani KMD Z-skoru ile karşılaştırılmalıdır. ${ }^{[11,12]}$ Eğer Z-skoru $\leq-2$ standart sapmanın altında ise osteoporozdan, -1 ile -2 arasında ise osteopeniden bahsedilebilir. ${ }^{[9,13]}$

Yirmi yaş altındaki hastalar için DEXA kullanım rehberi geliştirilmiştir ${ }^{[14]} \mathrm{Bu}$ rehberde; osteoporoz tanısının sadece dansitometre ile konulmaması, ölçümlerde omurga ve total vücut ölçümünün tercih edilmesi, KMD'nin yaşa ve cinsiyete göre oluşturulan Z-skorlarına göre değerlendirilmesi, T-skorlarının bu yaş grubunda kesinlikle kullanılmaması, Z-skoru <-2 ise raporlamanın "kronolojik yaşa göre düşük kemik dansitesi" veya "yaşa göre beklenenden düşük değer" şeklinde yapılması, KMD değerinin bu yaş grubunda her zaman kırık olasılığını tam göstermeyeceği ve klinikte bu bilginin hatırda tutulması gerektiği, tekrarlayan ölçümlerin aynı cihaz, teknik ve bilgisayar programı ile yapılması gibi öneriler yer almaktadır. ${ }^{[15]}$

\section{MEDIKAL TEDAVI YAKLAŞIMI}

Erişkinlerde birçok alternatif bulunurken, çocukluk çağında tedavi seçenekleri oldukça kısıtlıdır. Günümüze kadar çocuklardaki osteopeni için genel kabul görmüş bir tedavi protokolü bulunmamaktadır. ilk önce kanıta dayalı doğru bir tanı koyulmalı, her olgu ayrı ayrı değerlendirilerek, tedavi ve takibi bireysel hale getirilmelidir. Sadece laboratuvar bulgularına bakarak osteoporoz tedavisine karar vermek doğru bir yaklaşım değildir.

Tedaviye başlamadan önce; ostepenik durumun aciliyeti, derecesi, primer ya da sekonder kaynaklı olup olmadığı belirlenmelidir. Tedavi kararı almak, ağır ve semptomları belirgin olgularda kolay iken, orta ve hafif olanlarda oldukça zordur. Ayrıntılı değerlendirmelerin ışığında; profilaksi, medikal, cerrahi ya da alternatif tedavi seçeneklerinden birisi tercih edilmelidir. Uzun zaman alan tedavilerin başarısı, multidisipliner yaklaşımda yatmaktadır.

Tedavinin amacı kemik kitlesini arttırmak, kırık riskini azaltmak, kırıkları ve kırıklara bağlı gelişebilecek deformiteleri önlemek, eşlik eden ağrıları ortadan kaldırmak, hastanın hareket yeteneğini ve yaşam kalitesini arttırmak, dengeli beslenmesini, fiziksel ve ruhsal gelişimini sağlamak olmalıdır.

Her hekimin öncelikli görevi, hastalıkların gelişmesine engel olmaktır. Osteopeniyi engellemenin yolu; riskli durumları akılda tutmaktan, mümkünse bunları ortadan kaldırmaktan, tümüyle ortadan kaldırılamayacaksa proflaktik (vitamin ve mineral) yaklaşımı devreye sokmaktan geçer. Bu sayede, hem hastalığın ve komplikasyonlarının önüne geçilmiş hem de erişkin dönem için yeterli pik kemik kitlesi elde edilmiş olur. 
Sekonder osteoporoz olgularında ise temel yaklaşım, altta yatan sorunu veya hastalığı tedavi etmektir (beslenme, endokrin, hormon, vitamin, mineral, kronik hastalık, metabolik hastalık, nörolojik sorunlar, ilaç kullanımı, kemoterapi ve radyoterapi vb.). Kronik hastalıklarda kemik mineral yoğunluk kaybına neden olan risk faktörleri düzeltildiği halde başarı elde edilemezse, osteoporozun derecesine uygun medikal tedaviye başlanmalıdır. ${ }^{[16,17]}$

Medikal tedavide kullanılan ilaçlar etki mekanizmalarına göre iki gruba ayrılır. Bir kısmı kemik yıkımını engellemekte (antiresorptifler: bifosfonatlar, kalsitonin), diğer bir kısmı ise kemik yapımını arttırmaktadır (anabolikler: büyüme hormonu, PTH) (Tablo 1). ${ }^{18]}$

Çocukluk çağında kullanımı ve deneyim sonuçları en fazla olan ilaçlardan birisi bifosfonatlardır. Bunlar parenteral ve oral yoldan kullanılabilir. Ağır derece osteoporozlarda, iv pamidronat uygun doz ve sürede kullanıldığında çok önemli kazanımlar elde edilmektedir. Özellikle osteogenezis imperfekta, glukokortikoide bağlı osteoporoz ve ileri derece serebral palsi olgularında pamidronat tedavisiyle, kırık sayısında ve ağrının şiddetinde azalma, kemik volümünde ve yaşam kalitesinde bir artış görülür. ${ }^{[19-21]}$ Bifosfonatların erken dönem yan etkileri iyi bilinmesine rağmen, uzun dönem olumsuz etkileri hakkında yeterli veri bulunmamaktadır. Tedaviye başlarken bunların göz önüne alınması, çocuklar için hala FDA onayının olmadığının bilinmesi ve yarar/zarar kıyaslamasının çok iyi yapılması gerekir.

\section{Hafif Derece Osteoporozun Tedavisi}

Bu olgularda herhangi bir kırık öyküsü olmamasına rağmen, klinik ve laboratuvar bulguları osteopeniyi (KMD Z-skoru -1 ile -2 arasında) destekler. Yapılması gereken; primer ya da sekonder osteopeni nedenlerini ortadan kaldırmak, ilaveten uygun dozda $D$ vitamini ve kalsiyuma başlamak, hastayı dengeli beslenme ve uygun fiziksel aktivitelere teşvik etmektir.

\section{Orta Derece Osteoporozun Tedavisi}

Orta derecede osteoporoza sahip (KMD Z-skoru $\leq-2$ ) hastalarda, eğer kırık sayısı az (vertebral kompresyon kırı̆gı yok, fakat 10 yaşına kadar iki ya da daha fazla, 19 yaşına kadar ise üç ya da daha fazla uzun kemik stres kırıkları olursa) fakat öykü, klinik ve laboratuvar bulguları uyumluysa, öncelikle altta yatan nedenler ortadan kaldırılmalı, D vitamini ve kalsiyuma uygun dozda başlanmalı, dengeli beslenme ve uygun fiziksel aktivite planlanmalıdır. Bu olgularda ağrı ön planda ise, spesifik tedavi olarak intranazal kalsitonine başlanabilir. Eğer kalsitonin kullanımına engel bir durum varsa, istenmeyen bir yan etki ortaya çıkmış ya da beklenen yarar elde edilememişse, oral bifosfonat (alendronat) tedavisine geçilebilir.

\section{Ağır Derece Osteoporozun Tedavisi}

Ağır olgularda belirgin kemik kitle kaybı ve tekrarlayan kırıklar (KMD Z-skoru $\leq-2$, üst ekstremite uzun

Tablo 1. Çocuklarda osteopeni tedavisinde kullanılan ilaçlar

\begin{tabular}{|c|c|c|c|c|}
\hline & İlaç adı & Etki mekanizması & Doz & Yan etki \\
\hline \multirow{4}{*}{$\begin{array}{l}\text { Kemik yıkımını } \\
\text { engelleyenler }\end{array}$} & Bifosfonatlar: & Osteoklast inhibitörü & & \multirow{3}{*}{$\begin{array}{l}\text { Ateş, hipokalsemi, } \\
\text { grip belirtileri, üveit, } \\
\text { çene osteonekrozu, } \\
\text { osteopetrozis } \\
\text { Oral bifosfonat: özofajit, } \\
\text { reflü, gastrit, }\end{array}$} \\
\hline & a. Pamidronat disodyum & & $\begin{array}{l}\text { iv: } 0,5-1 \mathrm{mg} / \mathrm{kg} / \mathrm{doz} \\
3 \text { gün, } 2-4 \text { ayda bir }\end{array}$ & \\
\hline & b. Alendronat sodyum & & po: $5-10 \mathrm{mg} /$ gün & \\
\hline & Kalsitonin & Osteoklast inhibitörü & 100-200 U/gün nazal & $\begin{array}{l}\text { Rinit, burun kuruluğu, } \\
\text { epistaksis }\end{array}$ \\
\hline \multirow[t]{4}{*}{$\begin{array}{l}\text { Kemik yapımını } \\
\text { uyaranlar }\end{array}$} & Büyüme hormonu & Anabolik etki & $\begin{array}{l}\text { Büyüme hormonu eksikli } \\
\text { eşlik ediyorsa uygun dozda } \\
\text { kullanılabilir }\end{array}$ & \\
\hline & Sodyum florid & Osteoblast aktivatörü & $\begin{array}{l}\text { Bifosfonat tedavisiyle kullanımı } \\
\text { sonlandı }\end{array}$ & \\
\hline & $\begin{array}{l}\text { Hormon replasman tedavisi } \\
\text { (östrojen, testosteron) }\end{array}$ & Anabolik etki & $\begin{array}{l}\text { Hipogonadizm eşlik ederse uygun } \\
\text { dozda kullanılabilir }\end{array}$ & \\
\hline & PTH (teriparatide) & Anabolik etki & Çocuklarda kullanılmamakta & \\
\hline \multirow[t]{2}{*}{ Profilaksi } & Vitamin D & & D3 vit: 400-800 U/gün & \\
\hline & Kalsiyum & & $500-1500 \mathrm{mg} / \mathrm{gün}$ & \\
\hline
\end{tabular}


kemiklerinde iki ya da daha fazla kırık veya vertebral kompresyon kırığı) olduğu için, mutlaka spesifik tedavi başlanmalıdır. Spesifik tedavi, oral alendronat ya da intravenöz pamidronat olmalıdır. illaveten, altta yatan nedenlerle mücadele edilmeli, vitamin $D$, kalsiyum, dengeli beslenme ve hastanın yapabileceği fiziksel aktivitelere yer verilmelidir.

Çok ağır osteoporoz olgularında (KMD Z skoru $\leq-3$, tekrarlayan kırıklar, hareket kaybı ve deformiteleri), spesifik ilaç ve cerrahi tedavi birlikte yapılabilir. Özellikle, intravenöz pamidronat yüksek dozda ve daha sık aralıklarla verilebilir. Tedavi süresi klinik ve laboratuvar bulgularına göre planlanmalıdır. Ayrıca, hasta ve yakınları her aşamada mutlaka bilgilendirilmeli, ihtiyaç durumunda psikososyal destek sağlanmalıdır.

Sonuç olarak; çocuk ve adolesanlarda osteopeni için kesin kabul görmüş bir tedavi protokol yoktur. Bu konuda deneyimli hekimlerin görüşleri ve bireysel tedavi yaklaşımları önem kazanmaktadır. Temel yaklaşım; osteopeni riski olan durumları ve kişileri tespit etmek, önleyici yaklaşımlarla osteoporoz ve ilişkili durumlara engel olabilmektir.

\section{KAYNAKLAR}

1. Osteoporosis prevention, diagnosis, and therapy. $\mathrm{NIH}$ Consens Statement 2000;17(1):1-45.

2. Albright F, Reifenstein EC. Parathyroid glands and metabolic bone disease. Selected Studies. Maryland, Baltimore: Williams \& Wilkins; 1948. p.165-82.

3. Bianchi ML. Osteoporosis in children and adolescents. Bone 2007;41(4):486-95.

4. Zhang C, Liu Z, Klein GL. Overview of pediatric bone problems and related osteoporosis. J Musculoskelet Neuronal Interact 2012;12(3):174-82.

5. Hartman C, Hochberg Z, Shamir R. Osteoporosis in pediatrics. Isr Med Assoc J 2003;5(7):509-15.

6. Şen Y, Yeşilkaya E, Atçı B, Özkan E, Akarsu S. Osteoporozlu çocuk ve ergenlerin klinik özellikleri. Romatol Tıp Rehab 2008;19(1):6-10.

7. Bianchi ML. Causes of secondary pediatric osteoporosis. Pediatr Endocrinol Rev 2013;10(Suppl 2):424-36.
8. Alanay Y, Rimoin D. Chondrodysplasias. In: Rosen CJ, editor. Primer on the metabolic bone diseases and disorders of mineral metabolism, 7th ed. Washington, DC: American Society of Bone and Mineral Research; 2008. p.428-9.

9. Bachrach LK, Sills IN; Section on Endocrinology. Clinical report -bone densitometry in children and adolescents. Pediatrics 2011;127(1):189-94. Crossref

10. Karagüzel G, Özkan B. Pediatrik osteoporoz. Türkiye Klinikleri Fiziksel Tıp ve Rehabilitasyon Özel Dergisi 2012;5(3):73-8.

11. Goksen D, Darcan S, Coker M, Kose T. Bone mineral density of healthy Turkish children and adolescents. J Clin Densitom 2006;9(1):84-90.

12. Stagi S, Cavalli L, lurato C, Seminara S, Brandi ML, de Martino $\mathrm{M}$. Bone metabolism in children and adolescents: main characteristics of the determinants of peak bone mass. Clin Cases Miner Bone Metab 2013;10(3):172-9.

13. Rauch F, Plotkin H, DiMeglio L, Engelbert RH, Henderson RC, Munns C, Wenkert D, Zeitler P. Fracture prediction and the definition of osteoporosis in children and adolescents: the ISCD 2007 Pediatric Official Positions. J Clin Densitom 2008;11(1):22-8. Crossref

14. International Society for Clinical Densitometry (ISCD) Official Positions-Pediatric. http//www.iscd.org/officialpositions/2013-iscd-official-positions pediatric/

15. Gordon CM, Leonard MB, Zemel BS; International Society for Clinical Densitometry. 2013 Pediatric Position Development Conference: executive summary and reflections. J Clin Densitom 2014;17(2):219-24. Crossref

16. Golden NH, Abrams SA; Committee on Nutrition. Optimizing bone health in children and adolescents. Pediatrics 2014;134(4):e1229-43. doi: 10.1542/peds.2014-2173

17. Koo W, Walyat N. Vitamin D and skeletal growth and development. Curr Osteoporos Rep 2013;11(3):188-93. Crossref

18. SaraffV, HöglerW. ENDOCRINOLOGY AND ADOLESCENCE. Osteoporosis in children: diagnosis and management. Eur J Endocrinol 2015;173(6):R185-97. Crossref

19. Kim MJ, Kim SN, Lee IS, Chung S, Lee J, Yang Y, Lee I, Koh SE. Effects of bisphosphonates to treat osteoporosis in children with cerebral palsy: a meta-analysis. J Pediatr Endocrinol Metab 2015;28(11-12):1343-50. Crossref

20. Grissom LE, Kecskemethy HH, Bachrach SJ, McKay C, Harcke HT. Bone densitometry in pediatric patients treated with pamidronate. Pediatr Radiol 2005;35(5):511-7.

21. Przkora R, Herndon DN, Sherrard DJ, Chinkes DL, Klein GL. Pamidronate preserves bone mass for at least 2 years following acute administration for pediatric burn injury. Bone 2007;41(2):297-302. 